\title{
Evaluation of Commercial Agrochemicals as New Tools for Malaria Vector Control
}

\author{
Mark Hoppé $e^{\star_{a}}$, Ottmar F. Hueter ${ }^{b}$, Andy Bywater ${ }^{c}$, Philip Wege ${ }^{d}$, and Peter Maienfisch ${ }^{*}$
}

\begin{abstract}
Malaria is a vector-borne and life-threatening disease caused by parasites that are transmitted to people through the bites of infected female Anopheles mosquitoes. The vector control insecticide market represents a small fraction of the crop protection market and is estimated to be valued at up to $\$ 500$ million at the active ingredient level. Insecticide resistance towards the current WHOPES-approved products urgently requires the development of new tools to protect communities against the transmission of malaria. The evaluation of commercial products for malaria vector control is a viable and cost effective strategy to identify new malaria vector control products. Several examples of such spin-offs from crop protection insecticides are already evidencing the success of this strategy, namely pirimiphos-methyl for indoor residual sprays and spinosad, diflubenzuron, novaluron, and pyriproxifen for mosquito larvae control, a supplementary technology for control of malaria vectors. In our study the adulticidal activities of 81 insecticides representing 23 insecticidal modes of action classes, 34 fungicides from 6 fungicidal mode of action classes and 15 herbicides from 2 herbicidal modes of action classes were tested in a newly developed screening system. WHOPES approved insecticides for malaria vector control consistently caused $80-100 \%$ mortality of adult Anopheles stephensi at application rates between 0.2 and $20 \mathrm{mg}$ active ingradient (Al) litre ${ }^{-1}$. Chlorfenapyr, fipronil, carbosulfan and endosulfan showed the expected good activity. Four new insecticides and three fungicides with promising activity against adult mosquitoes were identified, namely the insecticides acetamiprid, thiamethoxam, thiocyclam and metaflumizone and the fungicides diflumetorin, picoxystrobin, and fluazinam. Some of these compounds certainly deserve to be further evaluated for malaria vector control. This is the first report describing good activity of commercial fungicides against malaria vectors.
\end{abstract}

Keywords: Adult mosquito screening $\cdot$ Aedes $\cdot$ Agrochemicals $\cdot$ Anopheles $\cdot$ Malaria $\cdot$ Vector control

\section{Introduction}

The conventional chemical-based crop-protection agrochemical market is currently valued at $\$ 51.655$ billion and the non-crop agrochemical market only $\$ 6.322$ billion. ${ }^{[1]}$ The vector control insecticide market represents a small fraction of the non-crop market and valued at up to $\$ 500$ million at the active ingredient level. ${ }^{[2]}$

In the vector control insecticide market only six insecticides, all pyrethroids, are recommended for use in insecticide treated nets (ITNs) and thirteen insecticides, belonging to only four chemical classes (pyrethroids, organophosphates, carbamates

\footnotetext{
${ }^{*}$ Correspondence: Prof. Dr. P. Maienfisch ${ }^{d}$, Dr. M. Hoppéa

E-mail: peter.maienfisch@syngenta.com,

mark.hoppe@syngenta.com

Syngenta Crop Protection AG

ansecticide Research Biology, Stein Research Centre, Schaffhauserstrasse, $\mathrm{CH}-4332$ Stein, Switzerland

bInsecticide Research Chemistry, Stein Research Centre, Schaffhauserstrasse, $\mathrm{CH}-4332$ Stein, Switzerland 'Lawn \& Garden R\&D, Schwarzwaldallee 215, $\mathrm{CH}-4002$ Basel, Switzerland

'Chemical Research Biology, Jealott's Hill International Research Centre, Bracknell, Berkshire, RG42 6EY, UK

${ }^{\mathrm{e}}$ Crop Protection Research, Schwarzwaldallee 215 , $\mathrm{CH}-4002$ Basel, Switzerland
}

and organochlorines), as indoor residual sprays (IRS). ${ }^{[3.4]}$ It is noteworthy that all these products represent only two distinct modes of actions: inhibition of acetylcholine esterase (organophosphates and carbamates) and disruption of the voltage-gated sodium channels (organochlorines and pyrethroids). Resistance towards the current solutions is increasing and already presents a major problem. New chemistries targeting new sites of action are urgently needed to enable rotation of products with different modes of action to manage resistance and to secure the best possible protection of people at risk from vector-borne disease.

Considerable change has occurred in the agrochemical industry since the time when pyrethroids, such as etofenprox ${ }^{[5,6]}$ in 1987, were introduced as new tools into the vector control market. Consolidation within the industry has resulted in a significant reduction in the number of research-driven agrochemical companies. Additionally, the focus of the leading companies has been triggered by growers' needs in the main market regions of Latin America, Asia, US and Europe and research was concentrated on delivery of broad-spectrum blockbuster compounds, as well as novel seeds and traits. This development has also been influenced by the steady increase in the $R \& D$ cost for a new active ingredient over the last two decades and has negatively impacted interest in minor markets such as vector control. [7]

Today, an R\&D investment of approximately \$280 million is necessary to bring a new crop protection product to market. ${ }^{[8]}$ The required R\&D investments to develop an insecticide specifically for the malaria vector control market, assuming a broad range of adulticidal applications and global registration, is estimated to be $\$ 70-150$ million, ${ }^{[9]}$ which is only marginally lower than for a broad spectrum crop protection compound, however, the sales potential is markedly less. Furthermore, the time taken to perform the necessary research and development work to introduce a new product onto the market would not differ significantly from the 10-12 years required for the agricultural sector. ${ }^{[8]}$ It is therefore not unsurprising that to date all the active ingredients used for malaria vector control market are spin-offs from agricultural uses, and that vector control R\&D is not a high priority for major agrochemical companies.

Many of the novel insecticides recently introduced to the market have been designed to have good plant-systemic properties. The physical-chemical properties required for this are high water solubility 
and low $\log$ P. Conversely ITN and IRS products require a high degree of tarsal contact activity which is typically associated with compounds with entirely different physical-chemical properties - notably high $\log \mathrm{P}-$ such as are found in the pyrethroid insecticides. ${ }^{[10]}$ Furthermore, if a compound is to be considered for inclusion within an ITN, it must also be thermally stable at the temperatures required to melt and extrude the polymer.

Our research has found that contact activity and rapid knockdown is relatively rare amongst insecticide chemistries. For example, the current leading class of insecticides, the neonicotinoids, are highly systemic which facilitates use patterns such as soil and seed treatment applications, but these chemicals often lack significant contact activity and are therefore less suitable for malaria vector control. ${ }^{[11]}$ Furthermore, the implications for disease transmission of slower acting classes such as pyrazolines and pyrroles must be considered. [12] The requirement for an enduring effect from an IRS treatment is also at odds with many of the contemporary insecticidal chemistries which have been optimized to reduce longevity for environmental reasons.

Despite this, some commercial crop protection products might be suitable for repurposing as new malaria vector control solutions. This strategy would benefit from the already established knowledge base, e.g. the registration dossier in relevant areas such as chemistry, production, and product safety which ultimately would result in strongly reduced $R \& D$ costs and registration timelines.

\section{Evaluation of Commercial Agrochemicals for Control of Adult Malaria Vectors}

Currently only 13 insecticides, belonging to four chemical classes and representing only two distinct modes of actions, are WHOPES approved for malaria adult vector control. These are the pyrethroids (mode of action: sodium channel modulators) lambda-cyhalothrin, alpha-cyperme- thrin, deltamethrin, etofenprox and permethrin; DDT (sodium channel modulator); the organophosphates (acetylcholinesterase inhibitors) fenitrothion, malathion and pirimiphos-methyl; and the carbamates (acetylcholinesterase inhibitors) bendiocarb and propoxur.[13-15] New tools for malaria vector control are urgently required to complement the current arsenal of vector control products for resistance management and to effectively protect people from risks of vector borne diseases.

Several research groups and crop protection companies have sought to evaluate commercial insecticides for mosquito control over the last few years. In 2006, Scott et al. ${ }^{[16]}$ reported on the toxicity of a small series of novel insecticides against Aedes aegypti and concluded that chlorfenapyr, hydramethylnon, indoxacarb, and imidacloprid warranted further evaluations as larvicides; diafenthiuron and chlorfenapyr for control of adult mosquitoes; and pyriproxyfen as potential mosquito growth regulator. In 2008 Pridgeon et al. ${ }^{[17]}$ assessed the relative potency of 19 pesticides against adult mosquitoes including Anopheles quadrimaculatus and found fipronil to have higher activity than permethrin, and abamectin, imidacloprid, diazinon, carbaryl, spinosad and chlorfenapyr to be only slightly less potent than permethrin against Anopheles quadrimaculatus. Furthermore their study revealed that different species of mosquitoes had different susceptibility to pesticides. Recently Devillers et al. ${ }^{[18]}$ applied the SIRIS multicriteria analysis to
129 insecticides in order to identify those having the best chance to potentially deliver a new larvicide and/or adulticide for mosquito control. Several interesting candidates were discussed, however, it was also concluded that a full risk assessment study was required for a final judgement. Furthermore, crop protection companies such as BASF, Bayer, Sumitomo, Syngenta and others have performed their own studies to evaluate the potential of their commercial insecticides for additional uses in vector control over the last two decades (see also Table 1 below).

The strategy for repurposing active ingredients with unique formulations has already resulted in the development of series of compounds for malaria vector control such as pirimiphos-methyl (organophosphate, acetylcholinesterase inhibitor) for IRS; ${ }^{[15]}$ and spinosad (fermentation product, nicotinic acetylcholine receptor allosteric modulator), diflubenzuron (benzoylurea, chitin biosynthesis inhibitor), novaluron (benzoylurea, chitin biosynthesis inhibitor) and pyriproxifen (juvenile hormone mimic, insect growth regulator) for mosquito larvae control, ${ }^{[19]}$ a supplementary technology to control malaria vectors. ${ }^{[20]}$ However, this strategy has not yet resulted in a new compound for ITN. In addition, a series of commercial insecticides are currently under WHOPES technical evaluation for malaria vector control (Table 1, Fig. 1). ${ }^{[21]}$ This list includes the insecticides chlorfenapyr, ${ }^{[22-25]}$ clothianidin, ${ }^{26,27]}$ and pyriproxifen. ${ }^{[28-31]}$

Table 1: New commercial insecticides currently under WHOPES evaluation for malaria vector control

\begin{tabular}{|l|c|c|c|c|}
\hline Product & Active Ingredient (AI) & \multicolumn{1}{c|}{ Company } & Application & Current phase \\
\hline SumiShield WG & Clothianidin & Sumitomo Chemical & IRS & 1 \\
\hline Fludora Fusion WP-SB & $\begin{array}{c}\text { Mixture of deltamethrin } \\
\text { and clothianidin }\end{array}$ & Bayer CS & IRS & 1 \\
\hline Interceptor G2 LN & $\begin{array}{c}\text { Mixture of alpha-cypermethrin } \\
\text { and chlorfenapyr }\end{array}$ & BASF & ITN & 2 \\
\hline SumiLarv & $\begin{array}{c}\text { Pyriproxifen } \\
\text { Mixture of permethrin } \\
\text { and pyriproxifen }\end{array}$ & Sumitomo Chemical & ITN & [26] \\
\hline Olyset Duo & Sumitomo Chemical & Larvicide & $2-3$ \\
\hline
\end{tabular}




\section{ACTELLIC ${ }^{\circledR}$ 300CS (Pirimiphos- methyl) for Control of Pyrethroid- resistant Mosquitoes}

At Syngenta the repurposing of commercial insecticides for control of adult malaria vectors has delivered ACTELLIC 300CS, a new solution for long-lasting control of pyrethroid resistant mosquitoes after indoor residual spraying (IRS), and has demonstrated the attractiveness of this strategy.

ACTELLIC 300CS is a new malaria vector control tool for IRS application. ${ }^{[32]}$ It is based on the active ingredient (AI) pirimiphos-methyl (Fig. 2) and shows high insecticidal efficacy and long residual activity against pyrethroid-resistant mosquitoes. ${ }^{[33,34]}$ Pirimiphos-methyl is an organophosphate insecticide introduced to the crop protection market by Syngenta in 1970, where it was originally used as broad-spectrum insecticide in a wide range of crop and non-crop applications.

The project to evaluate the potential of pirimiphos-methyl for the control of adult vectors via IRS and to develop a specific formulation for this use started in 2008 with funding from the Innovative Vector Control Consortium (IVCC) and was successfully completed by the end of 2012 . Modern micro-encapsulation technology was used to develop ACTELLIC 300CS, a formulation capable of providing at least 9 months' control on surfaces encountered in African habitations. By comparison, current alternatives to pyrethroids typically last only for three months after application, resulting in additional costs and complexity for malaria programs.

\section{Evaluation of Commercial Agrochemicals for Control of Adult Malaria Vectors}

In our study to evaluate the potential of commercial agrochemicals for malaria vectors control we included 81 insecticides (including 9 WHOPES approved insecticides for reference) representing 23 insecticidal mode of action classes. [34] Furthermore, we have tested 34 fungicides from 6 fungicidal mode of action classes ${ }^{[35]}$ and 15 herbicides from 2 herbicidal mode of action classes. ${ }^{[36]}$ These fungicides and herbicides were included because their modes of action are also of relevance to insect control and could be of interest in vector control.

For the evaluation of the selected agrochemicals a tiered screening approach was applied. The adulticidal activity of all compounds was initially accessed against an insecticide susceptible strain of Aedes aegypti. Compounds that caused mortality at a concentration of $\leq 200 \mathrm{mg}$ AI litre ${ }^{-1}$

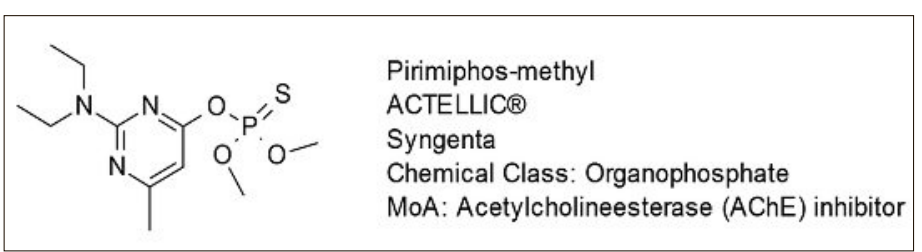

Fig. 2. Pirimiphosmethyl: The active ingredient of

ACTELLIC 300CS a new malaria vector control tool for IRS application.

$48 \mathrm{~h}$ after application were further tested against a pyrethroid susceptible strain of Anopheles stephensi for adult knockdown activity and mortality 24 and $48 \mathrm{~h}$ after application at concentrations of 200, 20,2 and $0.2 \mathrm{mg} \mathrm{AI} \mathrm{litre}{ }^{-1}$.

\section{Bioassays against Adult Aedes aegypti and Anopheles stephensi}

The compounds were applied to the base of wells as solutions in ethanol. After the ethanol had evaporated five adult female mosquitoes, three to five days old and non-blood fed, were placed in a treated well, then a retaining lid was used to prevent escape. Lids of the tissue culture plates were modified to hold small sections of cotton wool over each well in order to allow air exchange. The infested plates (Fig. 3) were held with the base at an angle of 60 degrees to the horizontal in a controlled environment chamber at $26^{\circ} \mathrm{C}$ and $60 \%$ relative humidity. The mosquitoes were assessed for knockdown one hour after introduction. Then, a small quantity of $10 \%$ sucrose solution was provided as a source of food and water. Mortality was assessed 24 and $48 \mathrm{~h}$ after introduction and recorded as $\mathrm{LC}_{80}$ values indicating the lowest concentration where at least $80 \%$ of the mosquitos were dead. A mosquito was recorded as 'dead' if it was unable to right itself when knocked onto its back or side.

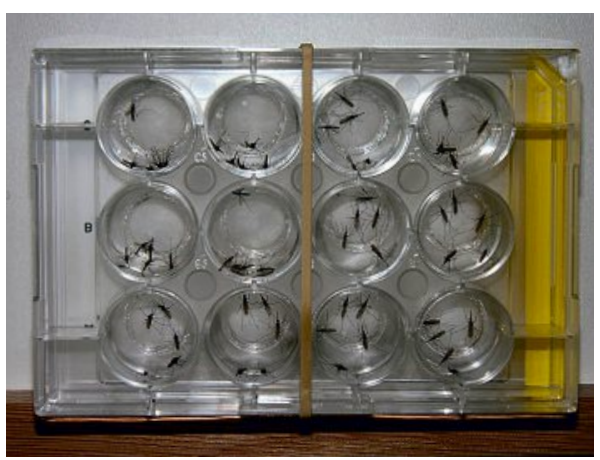

Fig. 3. Syngenta 12-well microtitre plate adult mosquito screening assay.

\section{Results and Discussion}

In our primary test 37 insecticides (Table 2), 7 fungicides (Table 3 ) and 1 herbicide (Table 4) were found to be active against Aedes aegypti at a concentrations of $\leq 200 \mathrm{mg} \mathrm{AI}$ litre $^{-1}$. The results of our secondary screening against a pyrethroid tolerant strain of Anopheles stephensi is shown in Table 5. A total of 9 compounds -6 insecticides (Fig. 4) and 3 fungicides (Fig. 5) displayed activity comparable to the WHOPES approved insecticides for malaria vector control.

\subsection{WHOPES Approved Insecticides for Malaria Vector Control}

The pyrethroids etofenprox, deltamethrin, lambda-cyhalothrin and alpha-cypermethrin consistently caused $80-100 \%$ mortality between 0.2 and $2 \mathrm{mg}$ AI litre ${ }^{-1}$ and knockdown activity at approximately $2 \mathrm{mg}$ AI litre ${ }^{-1}$ against Aedes aegypti and Anopheles stephensi (Table 5). Overall, lambda-cyhalothrin showed the greatest potency, whereas permethrin was somewhat weaker than the other pyrethroids. Adult mortality and knockdown activity of the carbamate bendiocarb and the organophosphates fenitrothion and pirimiphos-methyl were also in the range of 0.2 and $2 \mathrm{mg} \mathrm{AI} \mathrm{litre}{ }^{-1}$. Only DDT with an $\mathrm{LC}_{80}$ of $20 \mathrm{mg} \mathrm{AI} \mathrm{litre}{ }^{-1}$ was somewhat weaker in our assays. From these data we concluded that compounds with $\mathrm{LC}_{80}$ values of $\leq 20 \mathrm{mg}$ AI litre ${ }^{-1}$ deserve further evaluation as potential candidates for IRS or ITN applications in malaria vector control. Selection criteria to be considered in such an evaluation include the ease of formulation and polymer coating or incorporation, activity and durability of the treated polymer or the IRS formulation, potential for cross-resistance, cost efficiency, toxicity, and ecotoxicity.

\subsection{Other Insecticides}

Products belonging to twelve mode of action classes displayed activity at $200 \mathrm{mg}$ $\mathrm{AI}$ litre ${ }^{-1}$ in the primary test against Aedes aegypti (Table 2). No active compounds were identified amongst juvenile hormone mimics, TRPV channel modulators, mite growth inhibitors, inhibitors of chitin biosynthesis type 0 , moulting disruptors, ecdysone receptor agonists, mitochondrial complex I inhibitors, mitochondrial complex II inhibitors, mitochondrial complex III inhibitors, ACCase inhibitors, as well as among the tested compounds with unknown modes of action. These findings confirmed that mainly compounds affecting the insect nervous system offer the greatest potential to deliver adult control of mosquitoes. 

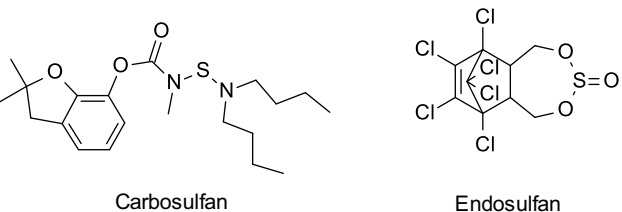

Origin: FMC

Chemical class: Carbamate

LC 80 An. stephensia): $\leq 0.2$

Knockdown activity ${ }^{b}$

MoA: AChE inhibitor

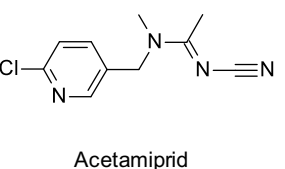

Origin: Nippon Soda

Chemical class: Neonicotinoid

LC80 An. stephensia): 20

No knockdown activity ${ }^{\text {b) }}$

MoA: Modulator of nAChR

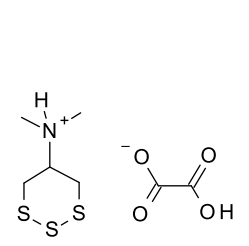

Thiocyclam hydrogenoxalate

Origin: Sandoz (now Arysta and Nippon Kayaku) Chemical class: Nereistoxin analogue

LC 80 An. stephensia): 20

Knockdown activity b)

MoA: Blocker of nAChR

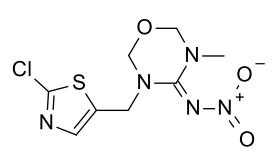

Thiamethoxam

Origin: Ciba (now Syngenta) Chemical class: Neonicotinoid LC $_{80}$ An. stephensia): 20 No knockdown activity ${ }^{\text {) }}$ MoA: Modulator of nAChR

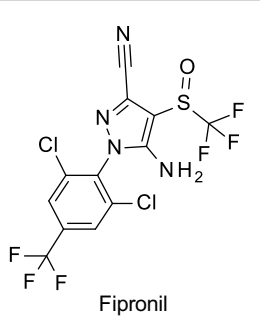

Origin: Rhone-Poulenc (now BASF) Chemical class: Phenylpyrazole $\mathrm{LC}_{80}$ An. stephensia): 2 No knockdown activity ${ }^{\text {b) }}$ MoA: GABA-gated chloride channel blocker

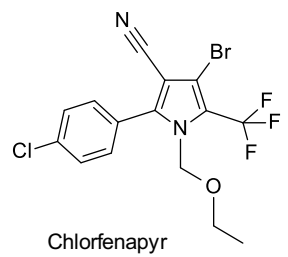

Origin: American Cyanamid (now BASF) Chemical class: Pyrrol LC 80 An. stephensia): 2 No knockdown activity ${ }^{\text {b) }}$

MoA: Uncoupler of oxidative phosphorylation

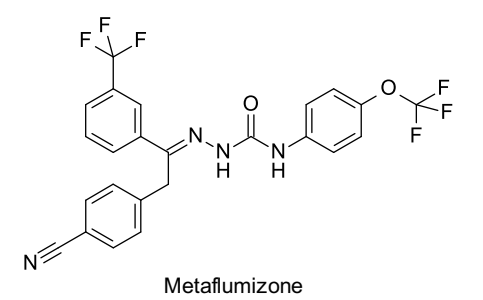

Origin: Nihon Nohyaku (licensed to BASF for some countries) Chemical class: Hydazine carboxamide

$\mathrm{LC}_{80}$ An. stephensia): 20

No knockdown activity ${ }^{\mathrm{b}}$

MoA: Blocker of voltage-dependent Na channel

Fig. 4. Most active insecticides for the control of adult Anopheles stephensi beyond the WHOPES approved compounds. a) $\mathrm{LC}_{80}$ in mg Al litre ${ }^{-1}$ against Anopheles stephensi after $48 \mathrm{~h}$ - lowest measured concentration at which at least $80 \%$ of the mosquitoes were killed. b) Knockdown against Anopheles stephensi determined after $1 \mathrm{~h}$; concentration $\leq 200 \mathrm{mg} \mathrm{Al} \mathrm{litre}^{-1}$ at which at least $80 \%$ of the mosquitoes showed knocked-down.

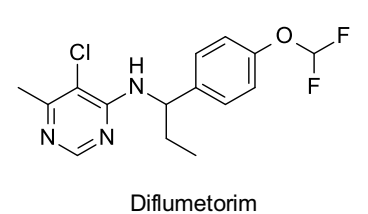

Origin: Ube (now SDS Biotech) Chemical class: Pyrimidine LC $_{80}$ An. stephensia): 20 Knockdown activityb) MoA: Mitochondrial complex I electron transport inhibitor

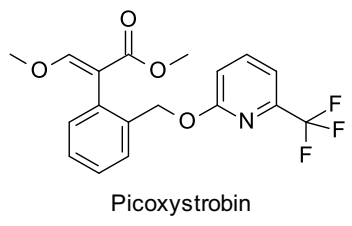

Origin: Zenca (now E.I. Du Pont de Nemours) Chemical class: Strobilurin LC $_{80}$ An. stephensia): 20

Knockdown activity ${ }^{\text {b) }}$

MoA: Mitochondrial complex III electron transport inhibitor

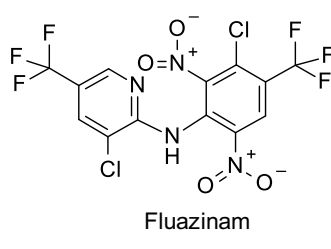

Origin: Ishihara Sangyo Kaisha Chemical class: Pyridine $\mathrm{LC}_{80}$ An. stephensia): 20 Knockdown activity ${ }^{\mathrm{b}}$ MoA: Uncoupler of oxidative phosphorylation

Fig. 5. Most active fungicides for the control of adult Anopheles stephensi. a) $\mathrm{LC}_{80}$ in mg Al litre ${ }^{-1}$ against Anopheles stephensi after $48 \mathrm{~h}$ - lowest measured concentration at which at least $80 \%$ of the mosquitoes were killed. b) Knockdown against Anopheles stephensi determined after $1 \mathrm{~h}$; concentration $\leq 200 \mathrm{mg} \mathrm{Al} \mathrm{litre}^{-1}$ at which at least $80 \%$ of the mosquitoes showed knocked-down.

AChE inhibitors: In our testing system the carbamate carbosulfan (Fig. 4) was found to be as potent as the WHOPES approved organophosphates and carbamates, but cross-resistance and product safety considerations do not suggest further evaluation of carbosulfan for malaria vector control. Formetanate and pirimicarb were $\geq 100$ times less active than the WHOPES approved AChE inhibitors.
GABA-gated chloride channel blockers: Endosulfan and fipronil (Fig. 4) were highly potent against mosquitoes, but both lacked knockdown activity against Anopheles stephensi. Fipronil was extensively evaluated for mosquito control, but has not yet entered the market, most probably due to stewardship issues around its use in or on a bed net. The close analogue ethiprole showed much weaker activity than fipronil. The organochlorine endosulfan was biologically active, but showed cross-resistance to dieldrin, and this resistance mechanism is widespread in field mosquito populations. Furthermore, it has been classified as a persistent organic pollutant (POP) under the Stockholm Convention and should therefore not be considered for use in vector control.

nAChR competitive modulators: The neonicotionoids are currently the most successful class of insecticides in crop protection. Their physical-chemical properties, which confer plant systemicity, are not ideal for adult vector control. Despite this two neonicotionoids, namely acetamiprid and thiamethoxam, displayed good activity $\left(\mathrm{LC}_{80}=20 \mathrm{mg}\right.$ AI litre $\left.{ }^{-1}\right)$ against Anopheles stephensi (Fig. 4). Imidacloprid and nitenpyram were only weakly active, and the most recent market products, sulfoxaflor, flupyradifurone and the development product triflumezopyrim were not

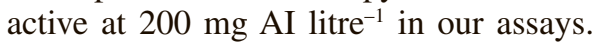
All tested neonicotinoids lacked knockdown activity.

$n A C h R$ allosteric modulators: The fermentation product spinosad and its semi-synthetic analogue spinetoram displayed only weak activity against adult mosquitoes. Their strength is more on larvicidal activity.

$n A C h R$ channel blockers: Thiocyclam (Fig. 4), an analogue of the natural toxin nereistoxin, showed knockdown activity and mortality at $20 \mathrm{AI} \mathrm{mg} \mathrm{litre}{ }^{-1}$ and reached the performance level of DDT. In our study thiocyclam was one of the most efficacious commercial insecticides not yet used in malaria vector control. However, it is questionable if the thermal stability of this compound would be sufficient for inclusion within an ITN. Its analogue cartap was only weakly active.

$\mathrm{GluCl}$ allosteric modulators: In our test system the fermentation product abamectin and its semi-synthetic analogue emamectin benzoate were clearly less active than permethrin and other WHOPES approved products. Based on our results the potential of these compounds for adult vector control is estimated to be low.

Uncouplers of oxidative phosphorylation: Chlorfenapyr (Fig. 4) was active at 20 $\mathrm{mg}$ litre $^{-1}$ and $2 \mathrm{mg}$ litre ${ }^{-1} 24$ and $48 \mathrm{~h}$ after infestation, respectively, however, it did 
Table 2. Activity of commercial insecticides against Aedes aegypti

\section{Mode of action ${ }^{\mathrm{a}}$}

Acetylcholinesterase (AChE) inhibitors

GABA-gated chloride channel blockers

Sodium channel modulators

Nicotinic acetylcholine receptor (nAChR) competitive modulators

Nicotinic acetylcholine receptor (nAChR) allosteric modulators

Glutamate-gated chloride channel $(\mathrm{GluCl})$ allosteric modulators

Juvenile hormone mimics

Chordotonal organ TRPV channel modulators

Mite growth inhibitors

Inhibitors of mitochondrial ATP synthase

Uncouplers of oxidative phosphorylation

Nicotinic acetylcholine receptor

(nAChR) channel blockers

Inhibitors of chitin biosynthesis, type 0

Inhibitors of chitin biosynthesis, type 1

Moulting disruptors

Ecdysone receptor agonists

Mitochondrial complex III electron transport inhibitors

Mitochondrial complex I electron

transport inhibitors

Voltage-dependent sodium channel

blockers

Inhibitors of acetyl CoA carboxylase

(ACCase)

Mitochondrial complex II electron transport inhibitors

Ryanodine receptor modulators

Unknown
IRAC Cmdps active against

class Aedes aegypti at $\mathrm{LC}_{80} \leq 200^{b}$

1 Bendiocarb $^{c)}$

Carbosulfan

Formetanate

Pirimicarb

Fenitrothion ${ }^{c)}$

Pirimiphos-methyl ${ }^{c)}$

2 Endosulfan

Fipronil

Ethiprole

3 lambda-Cyhalothrin ${ }^{\mathrm{c})}$

alpha-Cypermethrin ${ }^{\mathrm{c})}$

Deltamethrin $^{c)}$

Etofenprox ${ }^{c)}$

Permethrin ${ }^{c)}$

DDT $^{c)}$

4 Acetamiprid

Imidacloprid

Nitenpyram

Thiamethoxam

Flupyradifurone

Sulfoxaflor

Triflumezopyrim

5 Spinosad

Spinetoram

6 Abamectin

Emamectin benzoate

7

$9,29-$

$10-$

12 Diafenthiuron

Azocyclotin

Cyhexatin

13 Chlorfenapyr

14 Thiocyclam hydrogenoxalate Cartap

15 -

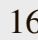

17

18

20

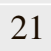

22

Indoxacarb (racemic)

Metaflumizone

23

25

28

Chlorantraniliprole

Cyantraniliprole

\section{$\mathrm{LC}_{80}{ }^{\mathrm{a}, \mathrm{b}}$ Cmpds not active against Aedes aegypti $\mathrm{LC}_{80} \geq 200^{b}$}

2

2

200

200

$\leq \mathbf{0 . 2}$

2

$\leq 0.2$

$\leq 0.2$

2

$\leq 0.2$

2

$\leq 0.2$

2

2

20

200

20

200

200

200

200

200

200

20

20

20

$-$

$-$

$-$

200

200

200

20

20

200

- Chlorfluazuron, Diflubenzuron, Flucycloxuron, Flufenoxuron, Noviflumuron, Teflubenzuron, Triflumuron

20

- Cyromazine

- Chromafenozide, Halofenozide, Methoxyfenozide, Tebufenozide

- Acequinocyl, Fluacrypyrim, Bifenazate

- Fenazaquin, Fenpyroximate, Pyridaben, Pyrimidifen, Tolfenpyrad

200

200

- $\quad$ Spirodiclofen, Spiromesifen, Spirotetramat

- Cyflumetofen, Cyenopyrafen, Pyflubumide

200 Flubendiamide

200

aFor details on the mode of action classes and the products see ref, [35]; ' ${ }^{2} C_{80}$ : Lowest applied dosage in mg Al litre ${ }^{-1}$ which provides $>80 \%$ mortality after 48 h. Concentrations tested: 200, 20, 2 and 0.2 mg Al litre ${ }^{-1}$; ${ }^{c W H O P E S}$ approved chemicals for bed net or indoor residual sprays for malaria vector control. 
Table 3. Activity of commercial fungicides against Aedes aegypti

\section{Mode of action}

Mitochondrial complex I electron transport inhibitors

Mitochondrial complex II electron transport inhibitors (SDHI)

Mitochondrial complex III electron transport inhibitors at Qo site

\begin{tabular}{|c|c|c|c|}
\hline $\begin{array}{l}\text { FRAC } \\
\text { code }\end{array}$ & $\begin{array}{l}\text { Cmdps active against Aedes } \\
\text { aegypti at } \mathrm{LC}_{80} \leq 200^{\mathrm{b}}\end{array}$ & $\mathrm{LC}_{80}{ }_{80}^{a, b}$ & $\begin{array}{l}\text { Cmpds not active against } \\
\text { Aedes aegypti } \mathrm{LC}_{80} \geq 200^{\mathrm{b}}\end{array}$ \\
\hline $\mathrm{C} 1$ & Diflumetorim & 200 & \\
\hline $\mathrm{C} 2$ & Penthiopyrad & 200 & $\begin{array}{l}\text { Bixafen, Boscalid, Carboxin, } \\
\text { Fluopyram, Flutolanil, Fluxa- } \\
\text { pyroxad, Furametpyr, Mepronil, } \\
\text { Penflufen, }\end{array}$ \\
\hline C3 & $\begin{array}{l}\text { Kresoxim-methyl } \\
\text { Flufenoxystrobin } \\
\text { Orysastrobin } \\
\text { Picoxystrobin }\end{array}$ & $\begin{array}{c}20 \\
20 \\
20 \\
200\end{array}$ & $\begin{array}{l}\text { Azoxystrobin, Coumoxystrobin, } \\
\text { Dimoxystrobin, Enoxastrobin, } \\
\text { Fenaminstrobin, Fluoxastrobin, } \\
\text { Mandestrobin, Metominostrobin, } \\
\text { Pyraclostrobin, Pyrametostrobin, } \\
\text { Pyraoxystrobin, Triclopyricarb, } \\
\text { Trifloxystrobin, Famoxadone, } \\
\text { Fenamidone, Pyribencarb }\end{array}$ \\
\hline $\mathrm{C} 4$ & - & - & Cyazofamid \\
\hline
\end{tabular}

C5 Fluazinam

C8
200

Ametoctradin

Mitochondrial complex III electron transport inhibitors at Qo site, stigmatellin binding sub-site

Mitochondrial complex III electron transport inhibitors at Qi site

aFor details on the mode of action classes and the products see ref. [36]; b $^{2} \mathrm{C}_{80}$ : Lowest applied dosage in mg Al litre ${ }^{-1}$ which provides $>80 \%$ mortality after 48 h. Concentrations tested: 200, 20, 2 and 0.2 mg Al litre-1. $^{-1}$

Table 4. Activity of commercial herbicides against Aedes aegypti

\section{Mode of action}

Inhibitors of acetyl CoA carboxylase (ACCase)

Inhibition of protoporphyrinogen oxidase (PPO)

\begin{tabular}{c|l}
$\begin{array}{c}\text { HRAC } \\
\text { class }\end{array}$ & $\begin{array}{l}\text { Cmdps active against Aedes } \\
\text { aegypti at } \mathrm{LC}_{\mathbf{8 0}} \leq \mathbf{2 0 0}^{\mathrm{b}}\end{array}$ \\
\hline $\mathrm{A}$ & - \\
\hline $\mathrm{E}$ & Halosafen
\end{tabular}

\section{$\mathrm{LC}_{80}{ }^{\text {a }}$ Cmpds not active against Aedes aegypti $\mathrm{LC}_{80} \geq 200^{\mathrm{b}}$}

- $\quad$ Fluazifop

200 Acifluorfen (acid), Bifenox, Butafenacil, Flumiclorac-pentyl, Flumioxazin, Fomesafen, Lactofen, Oxadiazon, Oxyfluorfen, Pentoxazone, Pyraflufen-ethyl, Saflufenacil, Sulfentrazone

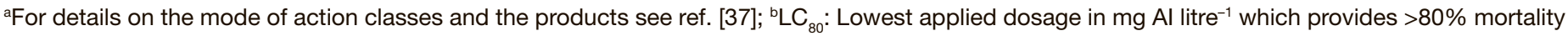
after 48 h. Concentrations tested: 200, 20, 2 and 0.2 mg Al litre $^{-1}$.

not show adult knockdown activity. The compound is currently under evaluation as a solo formulation for IRS and in mixture with alpha-cypermethrin for LLIN application by BASF (Table 1).

Voltage-dependent sodium channel blockers: Metaflumizone (Table 4) is slow acting and shows moderate activity $24 \mathrm{~h}$ after infestation. Indoxacarb was only active against Aedes aegypti, but not against Anopheles stephensi $24 \mathrm{~h}$ after infestation.

Compounds from the mode of action classes, mitochondrial ATP synthase inhibitors (difenthiuron, azocyclotin, cyhexatin), chitin biosynthesis inhibitors type 1 (buprofezin) and ryanodine receptor modulators (chlorantraniliprole, cyantraniliprole) showed only weak activity and did not display knockdown activities. Therefore, none of these products is con- sidered to offer an attractive potential for vector control.

\subsection{Fungicides}

Products belonging to four modes of action classes displayed activity at $200 \mathrm{mg}$ litre $^{-1}$ in the primary test against Aedes aegypti (Table 3). No active compounds were identified amongst mitochondrial complex III electron transport inhibitors acting at the Qi site or the Qo site (stigmatellin binding sub-site).

Mitochondrial complex I electron transport inhibitors: Diflumetorin (Fig. 5), the only fungicidal compound tested from this mode of action class, was active at 20 mg AI litre ${ }^{-1}$, whereas all the insecticides tested with this mode of action, namely fenazaquin, fenpyroximate, pyridaben, pyrimidifen and tolfenpyrad did not show any activity against Aedes aegypti at 20 mg AI litre ${ }^{-1}$ (Table 2). This confirms the value of evaluating commercial fungicides or fungicidal chemical classes possessing a mode of action relevant in the field of insect control.

Mitochondrial complex II electron transport inhibitors (SDHI): Among the SDHI inhibitors tested only penthiopyrad showed some weak activity against adult mosquitoes. It can be concluded that this class of compounds is of very low potential for malaria vector control.

Mitochondrial complex III electron transport inhibitors at Qo site: 20 commercial products were tested among which the strobilurin kresoxim-methyl, was found to possess weak activity, and picoxystrobin (Fig. 5), was the most efficacious compound controlling adult Anopheles 
Table 5. Activity of agrochemicals against Aedes aegypti and Anopheles stephensi

\begin{tabular}{|c|c|c|c|c|c|}
\hline \multirow[t]{2}{*}{ Compound } & \multicolumn{2}{|c|}{ Aedes aegypti } & \multicolumn{3}{|c|}{ Anopheles stephensi } \\
\hline & $\begin{array}{c}\mathrm{KD}_{80} \\
\text { Adult } \\
\text { knockdown }\end{array}$ & $\begin{array}{c}\mathbf{L C}_{80} \\
\text { Adult mortality, } \\
24 \mathrm{~h}^{\mathrm{b}}\end{array}$ & $\begin{array}{c}\mathbf{L C}_{80} \\
\text { Adult } \\
\text { knockdown }\end{array}$ & $\begin{array}{c}\mathbf{L C}_{80} \\
\text { Adult mortality, } \\
24 \mathrm{~h}^{\mathrm{b}}\end{array}$ & $\begin{array}{c}\mathbf{L C}_{80} \\
\text { Adult mortality, } \\
48 \mathrm{~h}^{\mathrm{c}}\end{array}$ \\
\hline Bendiocarb $^{\mathrm{e}}$ & 2 & 2 & 2 & $\leq 0.2$ & $\leq 0.2$ \\
\hline Carbosulfan & 2 & 2 & 2 & $\leq 0.2$ & $\leq 0.2$ \\
\hline Formetanate & $>200$ & 200 & $>200$ & 200 & 200 \\
\hline Pirimicarb & $>200$ & 200 & 200 & 20 & 20 \\
\hline Fenitrothion $^{\mathrm{e}}$ & 2 & $\leq 0.2$ & $\leq 0.2$ & $\leq 0.2$ & $\leq 0.2$ \\
\hline Pirimiphos-methyle) & $>200$ & 2 & 2 & $\leq 0.2$ & $\leq 0.2$ \\
\hline Endosulfan & $\leq 0.2$ & $\leq 0.2$ & $>200$ & 20 & 20 \\
\hline Fipronil & $>200$ & $\leq 0.2$ & $>200$ & 2 & 2 \\
\hline Ethiprole & $>200$ & 2 & $>200$ & $>200$ & 200 \\
\hline lambda-Cyhalothrin ${ }^{\mathrm{e}}$ & 2 & $\leq 0.2$ & 2 & $\leq 0.2$ & $\leq 0.2$ \\
\hline alpha-Cypermethrin ${ }^{\mathrm{e})}$ & 2 & 2 & 20 & 2 & 2 \\
\hline Deltamethrin ${ }^{\mathrm{e})}$ & 2 & $\leq 0.2$ & 2 & 2 & 2 \\
\hline Etofenprox ${ }^{\mathrm{e})}$ & 20 & 2 & 2 & 2 & 2 \\
\hline Permethrin $^{\mathrm{e}}$ & 20 & 2 & 20 & 20 & 20 \\
\hline $\mathrm{DDT}^{\mathrm{e}}$ & 20 & 20 & 20 & 20 & 20 \\
\hline Acetamiprid & $>200$ & 200 & $>200$ & 20 & 20 \\
\hline Imidacloprid & $>200$ & 200 & $>200$ & $>200$ & 200 \\
\hline Nitenpyram & $>200$ & 200 & $>200$ & 200 & 200 \\
\hline Thiamethoxam & $>200$ & 200 & $>200$ & 200 & 20 \\
\hline Flupyradifurone & $>200$ & 200 & $>200$ & $>200$ & $>200$ \\
\hline Sulfoxaflor & $>200$ & $>200$ & $>200$ & $>200$ & $>200$ \\
\hline Triflumezopyrim & $>200$ & $>200$ & $>200$ & $>200$ & $>200$ \\
\hline Spinosad & $>200$ & 200 & $>200$ & 200 & 200 \\
\hline Spinetoram & $>200$ & 200 & $>200$ & 200 & 200 \\
\hline Abamectin & $>200$ & 200 & $>200$ & 200 & 20 \\
\hline Emamectin benzoate & $>200$ & 200 & $>200$ & $>200$ & 200 \\
\hline Diafenthiuron & $>200$ & $>200$ & $>200$ & 200 & 200 \\
\hline Azocyclotin & $>200$ & 200 & $>200$ & $>200$ & 200 \\
\hline Cyhexatin & $>200$ & 200 & $>200$ & 200 & 200 \\
\hline Chlorfenapyr & $>200$ & 20 & $>200$ & 20 & 2 \\
\hline Thiocyclam hydrogenoxalate & 200 & 20 & 20 & 20 & 20 \\
\hline Cartap & 200 & 200 & $>200$ & 200 & 200 \\
\hline Buprofezin & $>200$ & 20 & $>200$ & $>200$ & $>200$ \\
\hline Indoxacarb (racemic) & $>200$ & $>200$ & $>200$ & $>200$ & $>200$ \\
\hline Metaflumizone & $>200$ & $>200$ & $>200$ & $>200$ & 20 \\
\hline Chlorantraniliprole & $>200$ & 200 & $>200$ & $>200$ & $>200$ \\
\hline Cyantraniliprole & $>200$ & $>200$ & $>200$ & 200 & 200 \\
\hline Diflumetorim & 20 & 200 & 20 & 20 & 20 \\
\hline Penthiopyrad & $>200$ & $>200$ & $>200$ & $>200$ & $>200$ \\
\hline Kresoxim-methyl & 200 & 200 & $>200$ & 200 & 200 \\
\hline Flufenoxystrobin & $>200$ & $>200$ & $>200$ & $>200$ & $>200$ \\
\hline Orysastrobin & $>200$ & 20 & $>200$ & $>200$ & $>200$ \\
\hline Picoxystrobin & $>200$ & 200 & 200 & 20 & 20 \\
\hline Fluazinam & $>200$ & $>200$ & 200 & 20 & 20 \\
\hline Halosafen & $>200$ & $>200$ & $>200$ & $>200$ & $>200$ \\
\hline
\end{tabular}

${ }^{a} \mathrm{KD}_{80}$ : Lowest applied dosage in $\mathrm{mg} \mathrm{Al} \mathrm{litre-1}$ which provides > 80\% knock-down effects after $1 \mathrm{~h}$. Concentrations tested: 200, 20, 2 and $0.2 \mathrm{mg} \mathrm{Al}$ litre ${ }^{-1}$; bLC $_{80}$ : Lowest applied dosage in $\mathrm{mg} \mathrm{Al} \mathrm{litre}^{-1}$ which provides $>80 \%$ mortality after $24 \mathrm{~h}$. Concentrations tested: $200,20,2$ and $0.2 \mathrm{mg} \mathrm{Al} \mathrm{litre}{ }^{-1}$; ${ }^{\circ} \mathrm{LC}_{80}$ : Lowest applied dosage in $\mathrm{mg} \mathrm{Al} \mathrm{litre}{ }^{-1}$ which provides $>80 \%$ mortality after $48 \mathrm{~h}$. Concentrations tested: $200,20,2$ and $0.2 \mathrm{mg} \mathrm{Al} \mathrm{litre}{ }^{-1} ; \mathrm{d} A d u l t$ mortality against Aedes aegypti after $48 \mathrm{~h}$ is shown in Tables 1-3; eWHOPES approved chemicals for bed net or indoor residual sprays for malaria vector control. 
stephensi at $20 \mathrm{mg}$ AI litre ${ }^{-1}$. This is the first report on the valuable activity of strobilurin fungicides for vector control.

Uncouplers of oxidative phosphorylation: Surprisingly, the fungicide fluazinam was almost as active as chlorfenapyr, a commercial insecticide known to act as uncoupler of oxidative phosphorylation. Chlorfenapyr is currently under evaluation for ITN use (Table 1). These results suggest that the potential of fluazinam for malaria vector control should be further evaluated.

\subsection{Herbicides}

15 commercial herbicides, 1 ACC inhibitor and 14 PPO inhibitors were tested. Only one compound, the PPO inhibitor halosafen showed some weak activity against Aedes aegypti.

\section{Summary and Conclusions}

The vector control insecticide market represents a small fraction of the crop protection market and is estimated to be worth up to $\$ 500$ million at the active ingredient level. Currently only 13 insecticides, belonging to four chemical classes and representing only two distinct modes of actions, are WHOPES approved for malaria adult vector control. Resistance towards the current solutions is increasing and already presents a major problem. New chemistries targeting new sites of action are urgently needed to enable rotation of products with different modes of action to manage resistance and to secure the best possible protection of people at risk from vector borne diseases. The evaluation of commercial products for malaria vector control uses is a viable and cost-effective strategy to find new malaria vector control products. Several examples of such spin-offs from crop protection insecticides are evidencing the success of this strategy, namely pirimiphos-methyl for IRS and spinosad, diflubenzuron, novaluron, pyriproxifen, and pirimiphos-methyl for mosquito larvae control, a supplementary technology to control malaria vectors.

In our study 81 insecticides representing 23 insecticidal modes of action classes, 34 fungicides from 6 fungicidal mode of action classes and 15 herbicides from 2 herbicidal modes of action classes were included and the adulticidal activity against Aedes aegypti and Anopheles stephensi was evaluated. The WHOPES approved insecticides for malaria vector control showed $80-100 \%$ mortality at application rates between 0.2 and $20 \mathrm{mg}$ AI litre ${ }^{-1}$. From our results we conclude that compounds with $\mathrm{LC}_{80}$ values of $\leq 20 \mathrm{mg}$ AI litre ${ }^{-1}$ deserve further evaluation as potential candidates for IRS or ITNs applications in malaria vector control.

The insecticides carbosulfan, endosulfan, fipronil, acetamiprid thiamethoxam, chlorfenapyr, thiocyclam, and metaflumizone reached this level of potency. Among these compounds carbosulfan, endosulfan and fipronil are not considered to be valuable candidates due to cross-resistance and product safety considerations. Chlorfenapyr is currently under evaluation in a mixture with alpha-cypermethrin for ITN by BASF. The neonicotinoids acetamiprid and thiamethoxan, the nAChR channel blocker thiocyclam and sodium channel blocker metaflumizone are newly identified compounds with interesting potential for malaria vector control that deserve further evaluation.

The fungicides diflumetorin (complex I inhibitor), picoxystrobin (complex III inhibitor), and fluazinam (uncoupler) were found to control Aedes aegypti and Anopheles stephensi at an application rate of $20 \mathrm{mg}$ AI litre ${ }^{-1}$. These compounds and the corresponding fungicidal chemical classes are certainly worth further evaluation for use in malaria vector control.

\section{Acknowledgments}

The authors would like to thank Mr Israel Tsegaye Beyene and Ms Nicoleta Daems for their valuable assistance in undertaking the bioassays presented in this paper. We also thank the Innovative Vector Control Consortium, especially Prof. Dr. Trevor Perrior, Dr. Colin Ruscoe, Dr. Robert Sloss and Dr. Sarah Rees for fruitful discussions and a great collaboration over the past few years.

Received: August 19, 2016

[1] Phillips McDougall, Industry Overview, 2013 Market, http://www.academia.edu/ 8024371/ Industry_Overview_of_timorex_gold. August 2015.

[2] J. Hemingway, Phil. Trans. Royal Soc. London, Series B, Bio. Sci. 2014, 369, 1645.

[3] R. Kamaraju, K. B. Tapan K. Barik, R. Niranjan, S. Poonam, P. D. Aditya, Parasitol Res. 2011, $108,757$.

[4] J. A. Turner, C. N. E. Ruscoe, T. R Perrior, CHIMIA 2016 70, 684.

[5] M. Prasittisuk, C. Prasittisuk, V. Pothichiti, B. Aum-aung, P. Mongklangkul, Southeast Asian J. Trop. Med. Public Health 1996, 27, 610.

[6] U. Sreehari, P. K. Mittal, R. K. Razdan, A. P. Dash, M. A. Ansari, Indian J. Med. Research 2009, 129, 593.

[7] P. Maienfisch, T. M. Stevenson, ACS Symposium Series 1204, 'Discovery and Synthesis of Crop Protection Products', 2016, 1. Eds. P. Maienfisch, T.M. Stevenson.

[8] Phillips McDougall, Agri Futura No. 198, 2016.

[9] J. Lucas, 'Outlooks on Pest Management', 2014, http://sumivector.com/sites/ default/files/ site-content/pdf/Outlook $\% 20$ Editorial\% 20 April\%202014.pdf

[10] D. A. Laskowski, Rev. Environ. Contam. Toxicol. 2002, 174, 49.

[11] N. Simon-Delso, V. Amaral-Rogers, L. P. Belzunces, J. M. Bonmatin, M. Chagnon, C.
Downs, L. Furlan, D. W. Gibbons, C. Giorio, V. Girolami, D. Goulson, D. P. Kreutzweiser, C. Krupke, M. Liess, E. Long, M. McField, P. Mineau, E. A. D. Mitchell, C. A. Morrissey, D. A. Noome, L. Pisa, J. Settele, J. D. Stark, A. Tapparo, H. van Dyck, J. van Praagh, J. P. van der Sluijs, P. R. Whitehorn, M. Wiemers, Envir. Sci. Pollution Res. 2015, 22, 5.

[12] K. Wellinga, A, C. Grosscurt, P. J. van Hes, J. Agric. Food Chem. 1977, 25, 987.

[13] WHOPES. WHO recommended insecticide products for treatment of mosquito nets for malaria vector control, 2016, http://www. who.int/whopes/Insecticides_ITN_Malaria_ Feb2016.pdf? ua=1, updated: 5 February 2016.

[14] WHOPES. WHO recommended long-lasting insecticidal nets, 2016, http://www.who.int/ whopes/Long-lasting_insecticidal_nets_ April_2016.pdf?ua=1, updated 1 April 2016.

[15] WHOPES. WHO recommended insecticides for indoor residual spraying against malaria vectors, 2015, http://www.who.int/whopes/ Insecticides_IRS_2_March_2015.pdf?ua=1, updated: 2 March 2015.

[16] A. Paul, L. C. Harrington, J. G. Scott, J. Med. Entomology 2006, 43, 55 .

[17] J. W. Pridgeon, R. M. Pereira, J. J. Becnel, S. A. Allan, G. G. Clark, J. Med. Entomology 2008, 45,82 .

[18] J. Devillers, L. Lagadic, O. Yamada, F. Darriet, R. Delorme, X. Deparis, J-P. Jaeg, C. Lagneau, B. Lapied, F. Quiniou, A. Yebakima, 'Juvenile Hormones and Juvenoids', Ed. J. Devillers, 2013, p. 347.

[19] WHOPES-recommended compounds and formulations for control of mosquito larvae, 2016, http://www.who.int/whopes/Mosquito larvicides_March_2016.pdf?ua $=1$, updated $1 \overline{8}$ March 2016.

[20] WHO, 'Larval Source Management - A supplementary measure for malaria vector control', 2013, http://apps.who.int/iris/ bitstream/10665/85379/1/9789241505604 eng.pdf

[21] WHOPES, Pecticide products under WHOPES laboratory and field testing and evaluation, 2016, http://www.who.int/whopes/Products Under_WHOPES_Evaluation_March_2016. $p d f ? u a=1$.

[22] BASF SE Professional \& Specialty Solutions, 'Malaria - beating the threat of insecticide resistance', 2015, https://industries.basf.com/ assets/global/corp/en/Agriculture/Pest $\% 20$ Control/BASF_malariaspecial_28-07-15.pdf

[23] WHOPesticide Evaluation Scheme (WHOPES). Report of the sixteenth WHOPES Working Group Meeting, 2013, http://apps.who.int/iris/ bitstream/10665/90976/1/9789241506304_ eng.pdf

[24] R. Kamaraju, T. K. Barik, P. Sharma, R. M. Bhatt, H. C. Srivastava, S. Uragayala, A. P. Dash, Malaria J. 2011, 10, 16.

[25] R. N'Guessan, C. Ngufor, A. A. Kudom, P. Boko, A. Odjo, D. Malone, M. Rowland, PLoS One 2014, 9, e87710/1.

[26] Sumitomo Chemical Company Limited, 'SumiShield® 50WG - A Breakthrough for Resistance Management', 2015, http://www. sumivector.com/sites/default/files/site-content/ pdf/SumiShield-Tech-brochure.pdf

[27] Bayer Vector Control, Public Health Journal, 2015, 26, https://issuu.com/bayervectorcontrol/ docs/phj_26-2015

[28] Sumitomo Chemical Co., Ltd, 'Recent Progress in the Research and Development of New Products for Malaria and Dengue Vector Control', 2015, http://www.sumitomo-chem. co.jp/english/rd/report/theses/docs/2015E_1. $p d f$

[29] C. Ngufor, R. N'Guessan, J. Fagbohoun, A. Odjo, D. Malone, M. Akogbeto, M. Rowland, PLoS One 2014, 9, e93603/1. 
[30] H. Kawada, G. O. Dida, K. Ohashi, E. Kawashima, G. Sonye, S. M. Njenga, C. Mwandawiro, N. Minakawa, PLoS One 2014, 9, e111195/1.

[31] Sumitomo Chemical Co. Ltd., SumiLarv Technical information, 2012, http://sumivector. com/sites/default/files/site-content/pdf/ SumiLarv_Technical_Brochure_2012.pdf

[32] Actellic CS fact sheet, http://www.ivcc.com/ download/file/fid/346 (Syngenta \& IVCC)

[33] R. M. Oxborough, J. Kitau, R. Jones, E. Feston, J. Matowo, F. W. Mosha, M. W. Rowland, Malaria J. 2014, 13, 37/1.
[34] M. Rowland, P. Boko, A. Odjo, A. Asidi, M. Akogbeto, R. N'Guessan, PLoS One 2013, 8, e69516.

[35] Insecticide Resistance Action Committee, Mode of Action Classification, http://www. irac-online.org/documents/moa-structuresposter-english/?ext=pdf accessed June 14, 2016; http://www.irac-online.org/documents/ moa-classification/ accessed June 14, 2016.

[36] Fungicide Resistance Action Committee, Mode of Action of Fungicides, http://www. frac.info/docs/default-source/publications/ frac-mode-of-action-poster/frac-moa- poster-2016.pdf?sfvrsn=2 accessed June 14, 2016; http://www.frac.info/docs/default-source/ publications/frac-code-list/frac-code-list-2016. $p d f ? s f u r s n=2$ accessed June 17, 2016.

[37] Herbicide Resistance Action Committee, The World of Herbicides, http://www.hracglobal. com/images/moaposter.pdf accessed June 14, 2016; http://www.hracglobal.com/pages/ classificationofherbicidesiteofaction.aspx accessed June 17, 2016. 